\title{
Calendário agrícola para a cultura do milho em Sinop (MT) ${ }^{1}$
}

\author{
Rodrigo Garcia Garcia², Rivanildo Dallacort², \\ Willian Krause ${ }^{2}$, Edenir Maria Serigatto ${ }^{3}$, Cleonir Andrade Faria Júnior ${ }^{2}$
}

\begin{abstract}
Agriculture calendar for the maize crop in Sinop, Mato Grosso State, Brazil

This study aimed at determining an agriculture calendar for the maize crop in Sinop, Mato Grosso State, Brazil, by evaluating rainfall, air temperature and evapotranspiration. Based on the thermal requirements of the maize hybrid, the heat unit accumulation or degree-day methods were used to determine the occurrence of phenological stages, considering the highest $\left(30^{\circ} \mathrm{C}\right)$ and lowest $\left(10^{\circ} \mathrm{C}\right)$ temperatures. The growing season was determined by analyzing the variation of the total 10-days average rainfall and evapotranspiration for that locality. The calendar was established according to the thermal requirements to complete the phenological stages, rainfall distribution during these stages and probability of occurring at least five dry days per 10-days period. The best sowing time took place between the 30th and 32nd 10 -days period, at the end of October and beginning of November.
\end{abstract}

KEY-WORDS: Rainfall; air temperature; evapotranspiration.

A região Centro-Oeste ocupa a segunda posição no cenário nacional, em produção de milho, tendo o Estado de Mato Grosso como principal produtor, com, aproximadamente, $46 \%$ da produção e mais de 1.650.000 hectares plantados (Conab 2010). Para se obter um bom rendimento na atividade agrícola, é necessário que haja uma interação importante entre as condições do meio ambiente e a cultura, desde antes do plantio até a pós-colheita, sendo a precipitação pluvial e a temperatura do ar, juntamente com o fotoperíodo, as principais variáveis meteorológicas decisivas, para a produtividade do milho.

A temperatura ambiente é o principal elemento climático que influencia diretamente na duração dos subperíodos de desenvolvimento das plantas.

\section{RESUMO}

O presente trabalho objetivou determinar um calendário agrícola para a cultura do milho, na microrregião de Sinop (MT), avaliando-se as seguintes variáveis: precipitação pluviométrica, temperatura do ar e evapotranspiração. Com base nas exigências térmicas de híbrido precoce, foi utilizado o método da soma térmica ou graus-dia, para definir a ocorrência dos estádios fenológicos, levando-se em consideração a temperatura superior $\left(30^{\circ} \mathrm{C}\right)$ e inferior $\left(10^{\circ} \mathrm{C}\right)$. A estação de crescimento foi determinada com base na variação dos totais médios decendiais da precipitação pluvial e evapotranspiração de referência, para a localidade. Para o estabelecimento do calendário, foram observadas as exigências térmicas necessárias para completar as fases fenológicas, a distribuição de precipitação pluvial durante estas fases e a probabilidade de ocorrência de, pelo menos, cinco dias secos, nos decêndios. A melhor época para a semeadura foi observada entre o $30^{\circ}$ e $32^{\circ}$ decêndios, no final de outubro e início de novembro.

PALAVRAS-CHAVE: Precipitação pluviométrica; temperatura do ar; evapotranspiração.

Para o cultivo do milho, não é diferente, sendo esta a principal causa de variações na duração do seu ciclo vegetativo, na ausência de deficiência hídrica acentuada (Barbano et al. 2003). O conhecimento da disponibilidade térmica de determinada localidade é de suma importância para definir épocas adequadas de semeadura e, consequentemente, diminuir os riscos à produção (Silva et al. 2007a).

Não menos importante, a precipitação pluviométrica também é um parâmetro essencial para determinar o sucesso de qualquer atividade agrícola, atuando, principalmente, sobre a necessidade de irrigação para as culturas e, consequentemente, dimensionamento de sistemas de irrigação (Longo et al. 2006). 
A distribuição gama de probabilidade é a mais utilizada para ajustar totais de chuva. Diversos estudos indicam a distribuição gama como o meio probabilístico mais confiável, na determinação de totais mensais de precipitação, como verificado por Murta et al. (2005), Sampaio et al. (2007) e Silva et al. (2007b), sendo seus estudos aplicados em diversas áreas, com destaque para a área de modelagem agrometeorológica, no planejamento agrícola.

Com base no estudo de graus-dia e precipitação pluviométrica, pode-se buscar a minimização de perdas para a cultura do milho, em regiões que apresentam carência de informações agroclimáticas. Este trabalho objetivou estabelecer, em função das exigências térmicas e hídricas da cultura do milho, um calendário agrícola para a microrregião do município de Sinop (MT), no médio norte do Estado de Mato Grosso - $12^{\circ} 12^{\prime} \mathrm{S}, 56^{\circ} 30^{\prime} \mathrm{W}$ e altitude de $415 \mathrm{~m}$ (Marcuzzo et al. 2011).

Os dados meteorológicos foram obtidos na Estação Meteorológica localizada na zona rural do município de Sinop (MT) e disponibilizados pelo Instituto Nacional de Meteorologia (Inmet). Foram utilizados dados diários de precipitação pluvial, umidade relativa do ar, velocidade do vento a 2,0 m (redução da velocidade do vento a 10,0 m), radiação solar incidente, evaporação e temperatura mínima, média e máxima do ar.

A série de dados utilizados compreende os anos de 1979 a 2009, sendo que a verificação de consistência, estimativa de evapotranspiração pelo método de Penman-Monteith-FAO e geração de médias decendiais de temperatura e precipitação foram efetuadas com o auxílio do software Clima (Faria et al. 2003). Devido à ocorrência de falhas no banco de dados, a sequência histórica de 1990 a 1997 foi excluída do estudo.

Com base nos valores diários de temperatura máxima e mínima do ar, foram calculadas as unida-

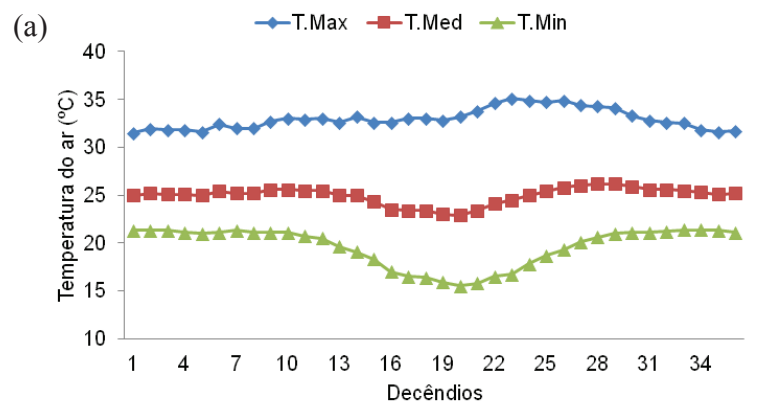

des térmicas de desenvolvimento (UTD) ou graus-dia (GD), conforme metodologia descrita por Brown (1969). A temperatura base considerada para o cálculo da soma térmica foi de $10^{\circ} \mathrm{C}$, para todo o ciclo da cultura, conforme recomendação de Berlato \& Matzenauer (1986), além de ser um dos valores de temperatura mais frequentemente encontrados em estudos desenvolvidos no Brasil (Fancelli \& Dourado Neto 2000).

Para se determinar as melhores épocas de semeadura, conforme a distribuição das precipitações, foi realizado um estudo de probabilidade de precipitação, utilizando-se o modelo probabilístico de distribuição gama incompleta, descrito por Thom (1958), a $75 \%$.

Com base na frequência dos dias secos, determinada por meio de uma série de dados meteorológicos disponíveis, calculou-se a probabilidade de ocorrência de, pelo menos, cinco dias secos nos decêndios.

A escolha das melhores épocas de semeadura do milho foi baseada nas exigências térmicas da cultura e na distribuição e quantidade de precipitação pluvial, durante os estádios fenológicos.

A variação média decendial das temperaturas máxima, mínima e média, na região, são apresentadas na Figura 1a. Verificou-se que a temperatura máxima apresentou seus maiores valores entre o $22^{\circ}$ (01-10 de agosto) e $29^{\circ}$ (11-21 de outubro) decêndios, com $34,6^{\circ} \mathrm{C}$ e $34,1^{\circ} \mathrm{C}$, respectivamente, sendo que o maior valor encontrado foi de $35,1^{\circ} \mathrm{C}$, no $23^{\circ}$ (11-21 de agosto) decêndio. Nos decêndios seguintes, os valores decresceram gradativamente, até o $1^{\circ}$ decêndio (1-10 de janeiro), que aparece com a menor média entre as máximas $\left(31,5^{\circ} \mathrm{C}\right)$, semelhantemente aos encontrados por Silva et al. (2007a), no município de Cascavel (PR), no verão, onde são obtidas as maiores produtividades do País.

As temperaturas médias apresentaram coeficiente de variação de apenas $3,2 \%$ e se mantiveram

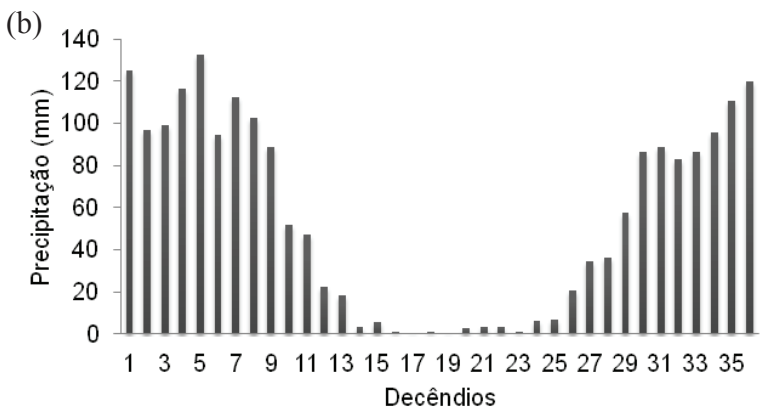

Figura 1. Médias decendiais das temperaturas máxima, média e mínima (a) e pluviométricas (\%) (b), no município de Sinop (MT). 
uniformes, sendo que apenas no inverno os valores se encontraram abaixo da média anual de $25^{\circ} \mathrm{C}$. As variações de temperatura encontradas na região, durante todo o ano, permaneceram dentro dos limites extremos tolerados pela cultura do milho, para sua plena atividade metabólica, compreendidos entre $10^{\circ} \mathrm{C}$ e $30^{\circ} \mathrm{C}$ (Cruz et al. 2006).

Para os valores de precipitação (Figura 1b), ocorreram 16 decêndios que apresentaram índices superiores a $80 \mathrm{~mm}$, compreendidos entre o $30^{\circ}$ (21-31 de outubro) e o $9^{\circ}$ (21-31 de março), os quais se encontram ininterruptos, constituindo, para essa região, uma ótima época para o cultivo de milho, somando $80 \%$ de toda a precipitação anual (aproximadamente $1.500 \mathrm{~mm}$ ), que, para Fancelli (2001), é mais que suficiente para suprir as exigências hídricas de dois ciclos da cultura do milho, já que, para cada ciclo, a necessidade fica entre $400 \mathrm{~mm}$ e $600 \mathrm{~mm}$ bem distribuídos. O $5^{\circ}$ decêndio (11-21 de fevereiro) apresentou a maior precipitação $(136 \mathrm{~mm})$.

Valores semelhantes foram encontrados por Dallacort et al. (2011) e Morreira et al. (2010), em outras regiões do Estado de Mato Grosso, porém, de forma menos acentuada, devido ao fato de os volumes das precipitações serem menores. Segundo Sousa et al. (2006), este comportamento é normal, dentro do território do Estado, visto que as áreas de maior pluviosidade correspondem ao extremo norte e noroeste, com totais médios anuais que variam de $2.100 \mathrm{~mm}$ a $2.500 \mathrm{~mm}$, valores semelhantes ao encontrado neste trabalho.

Para fins de planejamento das atividades e dimensionamento de projetos agrícolas, recomenda-se o estudo da precipitação provável ou esperada. Normalmente, sob irrigação, trabalha-se com a probabilidade de $75 \%$, ou seja, a chuva que se pode esperar em três a cada quatro anos, em determinado período do ano (Fietz et al. 2008).

Verificou-se que, a partir do $29^{\circ}$ decêndio, existe probabilidade mínima de $75 \%$ de ocorrer precipitação pluviométrica superior a $20 \mathrm{~mm}$, até o $9^{\circ}$ decêndio, caracterizando as melhores épocas para semeadura (Figura 2).

De acordo com Oliveira et al. (2000), as épocas em que há $75 \%$ de chance de ocorrer $20 \mathrm{~mm}$ de precipitação pluvial, no período móvel de 10 dias, podem ser consideradas preferenciais para a semeadura antecipada, uma vez que haverá maior probabilidade de acontecer precipitação pluvial. O estudo da probabilidade mínima de precipitação também

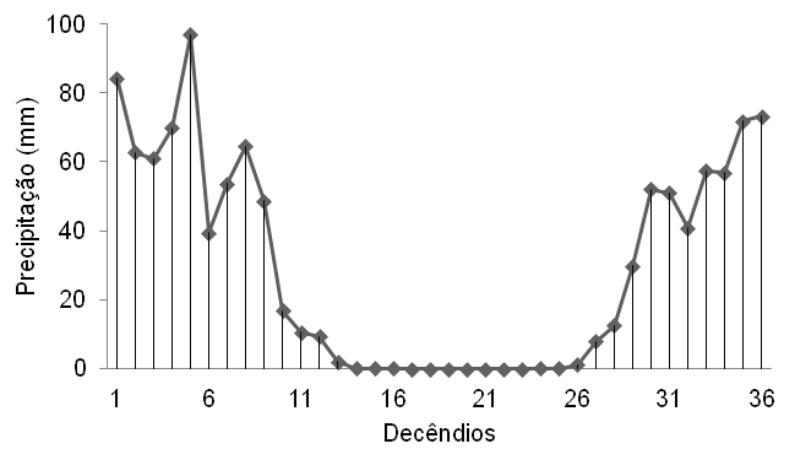

Figura 2. Probabilidade decendial de precipitação mínima de 75\%, no município de Sinop (MT).

deve ser levado em consideração para a cultura do milho, em seu estádio reprodutivo, iniciação floral, desenvolvimento da inflorescência e maturação fisiológica dos grãos, períodos que, para Figueredo Júnior (2004), são mais sensíveis e importantes para o rendimento produtivo.

Os valores médios de graus-dia acumulados (GDA) de cada decêndio não sofreram grandes oscilações, apresentando valor médio de 149,2, máximo de 170,7 e mínimo de 123,6 (Figura 3), sendo observada uma queda acentuada nas unidades térmicas de desenvolvimento apenas no inverno, explicada por Barbano et al. (2003) como uma necessidade encontrada pela cultura para manter seu pleno desenvolvimento.

Observou-se que, em regiões tropicais, como é o caso da região em estudo, o desenvolvimento fenológico da cultura do milho não sofre grande influência das variações na disponibilidade térmica, ao contrário do que ocorre em regiões de clima subtropical, como relatado por Almeida (2007).

Os valores mais satisfatórios de precipitação (Tabela 1), para o pleno desenvolvimento da cultura, foram encontrados na época de semeadura com início no final do mês de outubro e início de novembro (decêndios de 30 a 32). Neste período, há menor probabilidade de ocorrência de cinco ou mais dias secos no decêndio, durante a semeadura, e, consequentemente, menor risco de déficit hídrico, durante as fases de maior necessidade hídrica, que, segundo Fancelli \& Dourado Neto (2000), são observadas entre 15 dias antes e 15 dias após o aparecimento da inflorescência masculina.

Outro período crítico para a cultura do milho é o estádio de enchimento dos grãos, que ocorre, 


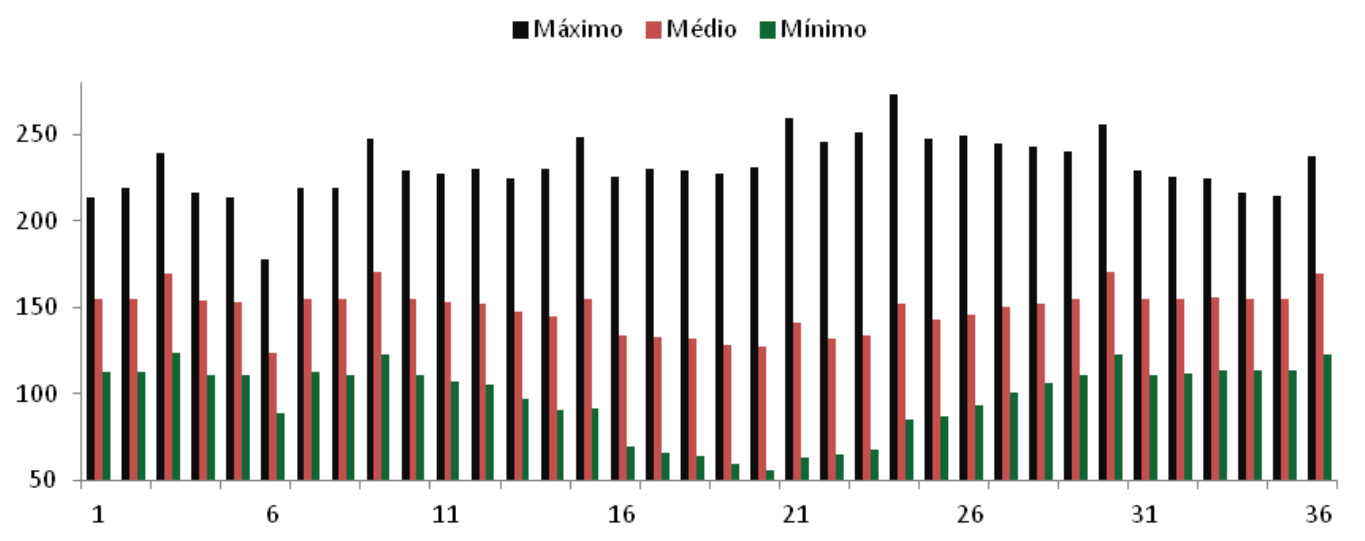

Figura 3. Valores máximos, médios e mínimos decendiais de graus-dia acumulados (GDA), no município de Sinop (MT).

Tabela 1. Frequência decendial absoluta de dias sem precipitação pluviométrica, no município de Sinop (MT).

\begin{tabular}{|c|c|c|c|c|c|c|c|c|c|c|c|c|}
\hline \multicolumn{13}{|c|}{ Número do decêndio } \\
\hline & 1 & 2 & 3 & 4 & 5 & 6 & 7 & 8 & 9 & 10 & 11 & 12 \\
\hline $\begin{array}{c}\text { Média } \\
\text { ponderada de } \\
\text { dias secos no } \\
\text { decêndio }\end{array}$ & 4,83 & 5,48 & 6,04 & 5,48 & 5,13 & 4,57 & 5,70 & 5,57 & 7,65 & 7,61 & 7,87 & 8,74 \\
\hline $\begin{array}{l}\text { Probabilidade } \\
(\%) \text { de haver } \\
5 \text { ou mais } \\
\text { dias secos no } \\
\text { período }\end{array}$ & 56,52 & 69,57 & 82,61 & 73,91 & 60,87 & 56,52 & 69,57 & 73,91 & 95,65 & 91,30 & 91,30 & 100,00 \\
\hline \multicolumn{13}{|c|}{ Número do decêndio } \\
\hline & 13 & 14 & 15 & 16 & 17 & 18 & 19 & 20 & 21 & 22 & 23 & 24 \\
\hline $\begin{array}{c}\text { Média } \\
\text { ponderada de } \\
\text { dias secos no } \\
\text { decêndio }\end{array}$ & 9,26 & 9,74 & 10,57 & 9,96 & 9,96 & 9,96 & 10,00 & 9,91 & 10,74 & 9,83 & 9,96 & 10,61 \\
\hline $\begin{array}{l}\text { Probabilidade } \\
(\%) \text { de haver } \\
5 \text { ou mais } \\
\text { dias secos no } \\
\text { período }\end{array}$ & 100,00 & 100,00 & 100,00 & 100,00 & 100,00 & 100,00 & 100,00 & 100,00 & 100,00 & 100,00 & 100,00 & 100,00 \\
\hline \multicolumn{13}{|c|}{ Número do decêndio } \\
\hline & 25 & 26 & 27 & 28 & 29 & 30 & 31 & 32 & 33 & 34 & 35 & 36 \\
\hline $\begin{array}{c}\text { Média } \\
\text { ponderada de } \\
\text { dias secos no } \\
\text { decêndio }\end{array}$ & 9,57 & 9,26 & 8,70 & 8,35 & 7,30 & 7,48 & 6,65 & 6,65 & 6,39 & 6,22 & 5,00 & 6,57 \\
\hline $\begin{array}{l}\text { Probabilidade } \\
(\%) \text { de haver } \\
5 \text { ou mais } \\
\text { dias secos no } \\
\text { período }\end{array}$ & 100,00 & 100,00 & 100,00 & 100,00 & 95,65 & 95,65 & 86,96 & 82,61 & 91,30 & 86,96 & 65,22 & 95,65 \\
\hline
\end{tabular}

normalmente, no final de janeiro e início de fevereiro, durante o verão. Segundo Didonet et al. (2001), quando os grãos são submetidos a altas temperaturas, durante a fase de acumulação de massa seca, a taxa efetiva de crescimento do grão é alta, resultando, normalmente, em grãos mais pesados. Por outro lado, quando a acumulação de massa seca nos grãos ocorre sob temperaturas mais amenas, a taxa de crescimento efetiva do grão é menor, resultando em grãos mais leves.

De maneira geral, a estação de melhor crescimento para a cultura do milho, na região de Sinop 
(MT), corresponde ao período úmido durante a primavera e o verão, que propícia grande disponibilidade hídrica ao solo, devido às precipitações pluviais e menor probabilidade de ocorrência de cinco ou mais dias secos.

A implantação da cultura do milho é apta para a região, com a melhor época para semeadura sendo observada entre o final de outubro e início de novembro, quando a alta disponibilidade térmica preconiza o menor tempo da cultura no campo, minimizando riscos climáticos da quebra de safra.

\section{REFERÊNCIAS}

ALMEIDA, M. Z. Simulação gráfica do crescimento de plantas de milho. 2007. 57 f. Dissertação (Mestrado em Engenharia Agrícola) - Universidade Federal de Santa Maria, Santa Maria, 2007.

BARBANO, M. T. et al. Temperatura base e soma térmica para cultivares de milho pipoca (Zea mays) no subperíodo emergência-florescimento masculino. Revista Brasileira de Agrometeorologia, Santa Maria, v. 11, n. 1, p. 79-84, 2003.

BERLATO, M. A.; MATZENAUER, R. Teste de um modelo de estimativa do espigamento do milho com base na temperatura do ar. Agronomia Sulriograndense, Porto Alegre, v. 22, n. 2, p. 243-259, 1986.

BROWN, D. M. Heat units for corn in Southern Ontario. Ontario: MAF, 1969.

COMPANHIA NACIONAL DE ABASTECIMENTO (Conab). Séries históricas relativas às safras 1976/77 a 2009/2010 de área plantada, produtividade e produção. 2010. Disponível em: $<\mathrm{http}: / /$ www.conab.gov.br/conteudos. php? $\mathrm{a}=1252 \& \mathrm{t}=2 \&$ Pagina_objcmsconteudos $=2 \# \mathrm{~A}$ objemsconteudos $>$. Acesso em: 20 out. 2010.

CRUZ, J. C. et al. Manejo da cultura do milho. Sete Lagoas: Embrapa Milho e Sorgo, 2006. (Circular técnica, 87).

DALLACORT, R. et al. Distribuição das chuvas no município de Tangará da Serra, médio norte do Estado de Mato Grosso, Brasil. Acta Scientiarum Agronomy, Maringá, v. 33, n. 2, p. 193-200, 2011.

DIDONET, A. D. et al. Crescimento e desenvolvimento de milho: acúmulo de massa seca do grão. Pesquisa Agropecuária Brasileira, Brasília, DF, v. 36, n. 3, p. 447456, 2001.

FANCELLI, A. L. Ecofisiologia de plantas de lavouras. In: CARLESSO, R. et al. Irrigação por aspersão no Rio Grande do Sul. Santa Maria: Ed. do Autor, 2001. p. 59-73.

FANCELLI, A. L.; DOURADO NETO, D. Produção de milho. Guaíba: Agropecuária Guaíba, 2000.
FARIA, R. T. et al. Clima: programa computacional para organização e análise de dados meteorológicos. Engenharia Agrícola, Jaboticabal, v. 23, n. 2, p. 372-387, 2003.

FIETZ, C. R. et al. Estimativa da precipitação provável para o Estado de Mato Grosso. Dourados: Embrapa, 2008. (Documentos, 87).

FIGUEREDO JÚNIOR, L. G. M. Modelo para estimação da produtividade de grãos de milho no Estado de São Paulo. 2004. 67 f. Tese (Doutorado em Agronomia) - Escola Superior de Agricultura "Luiz de Queiroz", Piracicaba, 2004.

LONGO, A. J.; SAMPAIO, S. C.; SUSZEK, M. Modelo computacional para estimativa das precipitações prováveis utilizando as distribuições de probabilidades gama e log-normal. Revista Varia Scientia, Cascavel, v. 6, n. 11, p. 141-148, 2006.

MARCUZZO, F. F. N. et al. Chuvas na Amazônia Matogrossense: análise histórica e tendência futura. Caminhos de Geografia, Uberlândia, v. 12, n. 38, p. 6575, 2011.

MOREIRA, P. S. P. et al. Distribuição e probabilidade de ocorrência de chuvas no município de Nova Maringá - MT. Revista de Ciências Agroambientais, Alta Floresta, v. 8, n. 1, p. 9-20, 2010.

MURTA, R. M. et al. Precipitação pluvial mensal em níveis de probabilidade pela distribuição gama para duas localidades do sudoeste da Bahia. Ciências Agrotécnicas, Lavras, v. 29, n. 5, p. 988-994, 2005.

OLIVEIRA, A. D. et al. Estação de crescimento e épocas de semeaduras para o arroz de sequeiro em algumas localidades de Minas Gerais. Engenharia Agrícola, Jaboticabal, v. 20, n. 1, p. 98-107, 2000.

SAMPAIO, S. C. et al. Estimativa e distribuição de precipitações decendiais para o Estado do Paraná. Irriga, Botucatu, v. 12, n. 1, p. 38-53, 2007.

SILVA, J. C. et al. Análise de distribuição de chuva para Santa Maria, RS. Revista Brasileira de Engenharia Agrícola e Ambiental, Campina Grande, v. 11, n. 1, p. 6772, $2007 \mathrm{~b}$.

SILVA, W. C. M. et al. Caracterização agroclimática da região de Cascavel - Paraná para o cultivo do milho. Ceres, Viçosa, v. 54, n. 313, p. 341-348, 2007 a.

SOUSA, R. R. et al. Estudo da variabilidade pluviométrica no extremo norte do Estado de Mato Grosso entre os anos de 1990 e 1996. Revista Geoambiente On-Line, Jataí, v. 1, n. 7, p. 89-107, 2006.

THOM, H. C. S. A note on the gama distribution. Monthly Weather Review, Washington, DC, v. 86, n. 4, p. 117-122, 1958. 